Supplement of

\title{
Evaporating brine from frost flowers with electron microscopy, and implications for atmospheric chemistry and sea-salt aerosol formation
}

Xin Yang ${ }^{1}$, Vilém Neděla ${ }^{2}$, Jiří Runštuk ${ }^{2}$, Gabriela Ondrušková ${ }^{3}$, Ján Krausko ${ }^{3}$, Lubica Vetrákováa $^{3}$, Dominik Heger ${ }^{3}$

1. British Antarctic Survey, Natural Environment Research Council, Cambridge, UK

2. Environmental Electron Microscopy Group, Institute of Scientific Instruments of the CAS, Brno, Czech Republic

3. Department of Chemistry, Faculty of Science, Masaryk University, Kamenice 5/A8, 62500 Brno

Research, and Centre for Toxic Compounds in the Environment (RECETOX), Masaryk University, Kamenice 5/A29, 62500 Brno

Correspondence to: Xin Yang (xinyang55@bas.ac.uk), Dominik Heger (hegerd@chemi.muni.cz)

S1 Video to complete Figure 3. Ice spikes sticking out from the main ice body. Imaged by ESEM AQUASEM II, Beam energy $20 \mathrm{keV}$, ionisation detector, water vapour pressure $348 \mathrm{~Pa}$, sample holder temperature $-5.2^{\circ} \mathrm{C}$, sample to aperture distance $2 \mathrm{~mm}$.

$\underline{\text { https://doi.org/10.5446/21430 }}$

S2 Video to complete Figure 5. Dynamical in-situ study of a large size $(\sim 100 \mu \mathrm{m})$ brine-covered piece of ice formation and breaking-off during slow evaporation of water. Imaged by ESEM AQUASEM II, beam energy 20 $\mathrm{keV}$, ionisation detector, water vapour pressure $348 \mathrm{~Pa}$, sample holder temperature $-5.2^{\circ} \mathrm{C}$, sample to aperture distance $2 \mathrm{~mm}$. 
S3: A chunk of salt formed on sample holder after a complete sublimation of a FF crystal in ESEM AQUASEM II. Beam energy $20 \mathrm{keV}$, ionisation detector, water vapour pressure $225 \mathrm{~Pa}$, sample holder temperature $-5.1{ }^{\circ} \mathrm{C}$.

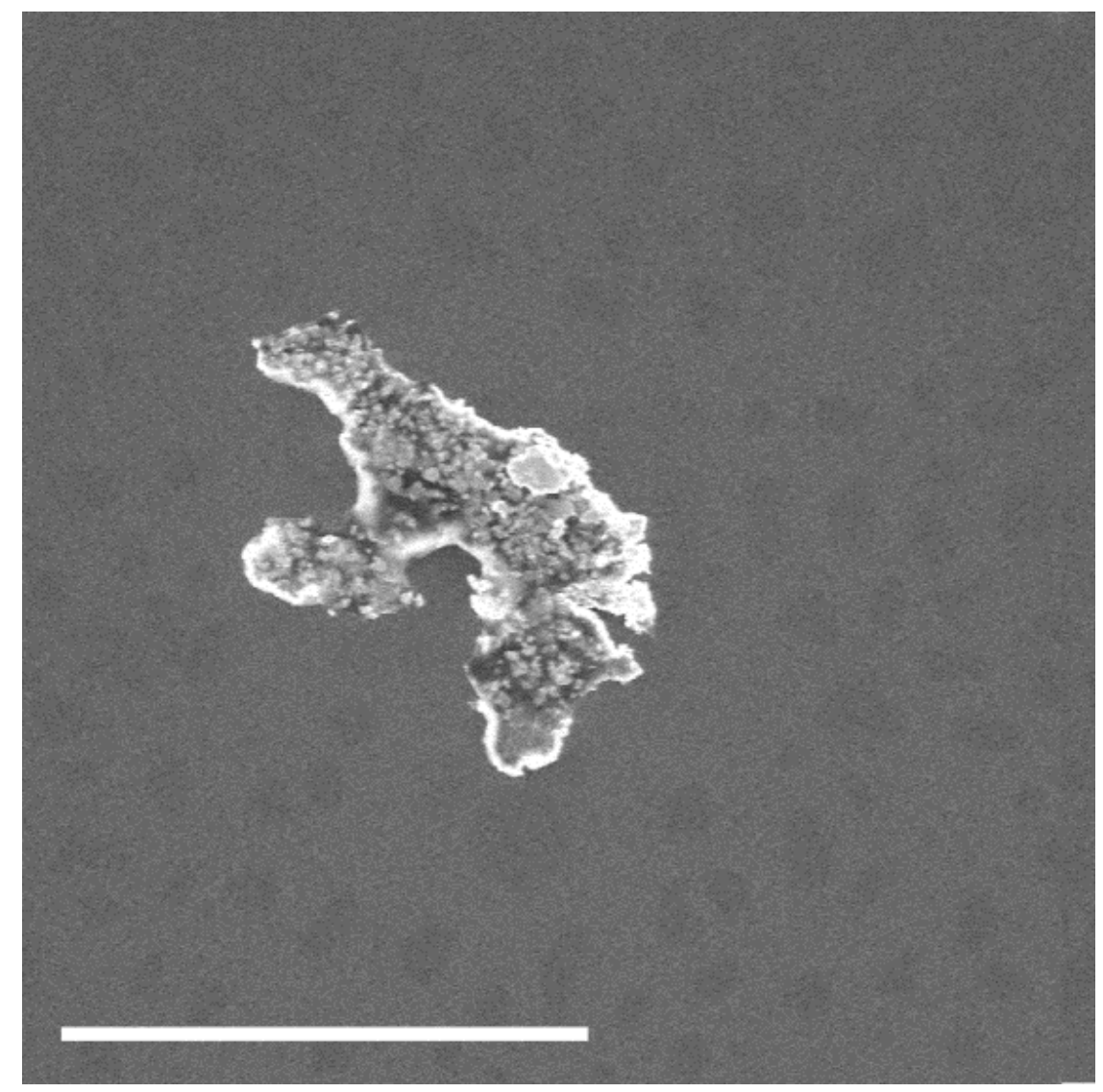

S4 Video to complete Figure 7. It demonstrates the flexibility of the fingers. ESEM AQUASEM II, Ionisation detector, air pressure $520 \mathrm{~Pa}$, sample holder temperature $-17.0^{\circ} \mathrm{C}$, sample to aperture distance $2 \mathrm{~mm}$.

https://doi.org/10.5446/21432

S5 A video of visualizing the formation of $\mathrm{NaCl}$ crystals on the top of the surface brine layer of $\mathrm{FF}$ related to Figure 8. ESEM AQUASEM II, Ionisation detector, air pressure $510 \mathrm{~Pa}$, sample holder temperature $-15.0^{\circ} \mathrm{C}$, sample to aperture distance $2 \mathrm{~mm}$.

https://doi.org/10.5446/21433 